\title{
Ethnopharmacological Survey on Phlomis grandiflora: In vivo Antihemorrhoidal Model
}

\author{
Ceylan Donmez ${ }^{1 \mathrm{a}}$, Ufuk Koca-Caliskan $^{1 \mathrm{~b}^{*}}$ \\ 1aDepartment of Pharmacognosy, Faculty of Pharmacy, Gazi University, 06330, Yenimahalle-Ankara, \\ Turkey, e-mail: ceylanaka@gazi.edu.tr \\ 1bDepartment of Pharmacognosy, Faculty of Pharmacy, Gazi University, 06330, Yenimahalle-Ankara, \\ Turkey, e-mail: ukoca@gazi.edu.tr
}

*Correspondence: ukoca@gazi.edu.tr, (Ufuk Koca-Caliskan)

Published: 29 July 2019

\begin{abstract}
Phlomis grandiflora H.S Thompson var. grandiflora, belongs to Lamiaceae family, has been utilized traditionally for the treatment of wound, inflammation, ulcer, diabetes and hemorrhoid mostly. Though hemorrhoids are so widespread in the world, studies on the prevention and treatment with natural pharmaceutical preparations of them are quite limited. People, who suffer from hemorrhoids, tries variety of self treatment methods such as utilizing animal products and homemade herbal preparations. Aim of this study is to evaluate the ethnopharmacological application of $P$. grandiflora on antihemorrhoidal activity of the leaf methanolic extract, which was applied topically (50\% cream) for 7 days onto rats having croton oil-induced hemorrhoid. Changes in the biochemical parameters such as TNF- $\alpha$ and VEGF showed that the plant extract is slightly more effective at healing hemorrhoids compared to the reference preparation. This is the first report revealing that the methanolic leaf extract of P. grandiflora showed topical antihemorrhoidal activity. When chemical studies are taken into consideration, it has been concluded that the plant extract containing a significant level of phenolic compounds, might be a promising source for the investigation of the antihemorrhoidal effect of medicinal plants, in the means of P. grandiflora, and related disturbances.
\end{abstract}

Key words: Ethnopharmacology, hemorrhoid, Phlomis, medicinal food, traditional medicine

\section{Introduction}

Phlomis species, belong to the Lamiaceae family, are widespread in Asia, Europe and North Africa, have been used traditionally for many years to treat wound, inflammation, ulcer, hemorrhoid and diabetes among the public (Amor et al., 2018). Phlomis grandiflora H.S Thompson var. grandiflora, known as "ballikotu, calba, çalba or şalba" in Anatolia, has been utilized mostly in a tea form due to its tonic appetizer, carminative and stimulant effects (Demirci et al., 2008) (Figure 1). Some Phlomis species have been externally-directly used for healing hemorrhoid in traditional medicine (Çalışkan et al., 2017). Studies have shown that the plant also have antiulcerogenic, antimicrobial, antifungal and potential neuroprotective activities (Gürbüz et al., 2003; Demirci et al., 2008). The plant includes mainly phenylethanoid, phenylpropanoid, iridoid glycosides and essential oils (Takeda et al., 1999; Çelik et al., 2005; Şenol et al., 2018). Hemorrhoids, which are the most common disorders in the community, described as vascular bleeding in the anus (Figure 2). Epidemiological studies on the prevalence of hemorrhoid disease arelimited. Nowadays, it is assumed that about $50 \%$ of people have 
hemorrhoidal diseases (Varut et al., 2012). To treat early stages of hemorrhoids, herbal products are quite effective, however they are insufficient to show the desired performance in more severe stages. Aesculus hippocastanum L. (horse chestnut), Malva sylvestris L. (mallow), Hammamelis virginiana L. (witch hazel) and Ruscus aculeatus L. (butcher's broom) are the most popular plants for treatment of hemorrhoids (Abascal et al., 2005; Aka-Dönmez et al., 2019).

Considering the usage of P. grandiflora in hemorrhoids and moreover in skin and mucosal disorders (Demirci et al., 2008), it is thought that traditional usage should be confirmed by in vivo experimental models in order to search its potential to be pharmaceutical preparation. In this study, antihemoroidal activity was evaluated. The aim of this study is to evaluate pharmacological and supporting biological activities of the P. grandiflora' leaf extract.

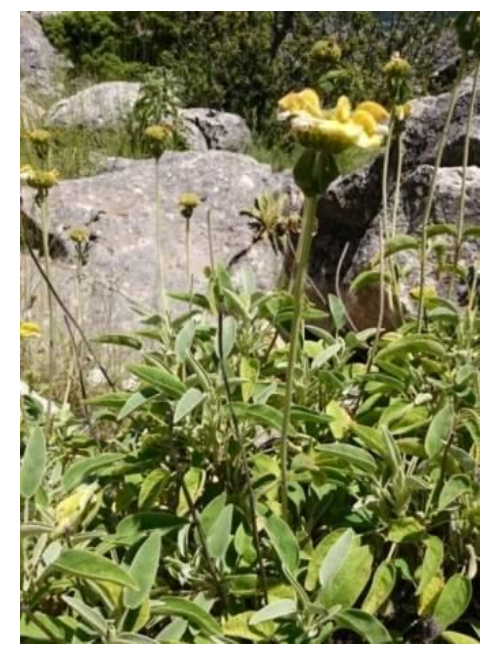

Figure 1. Phlomis grandiflora H.S Thompson var. grandiflora

(Beyşehir, Turkey in August)

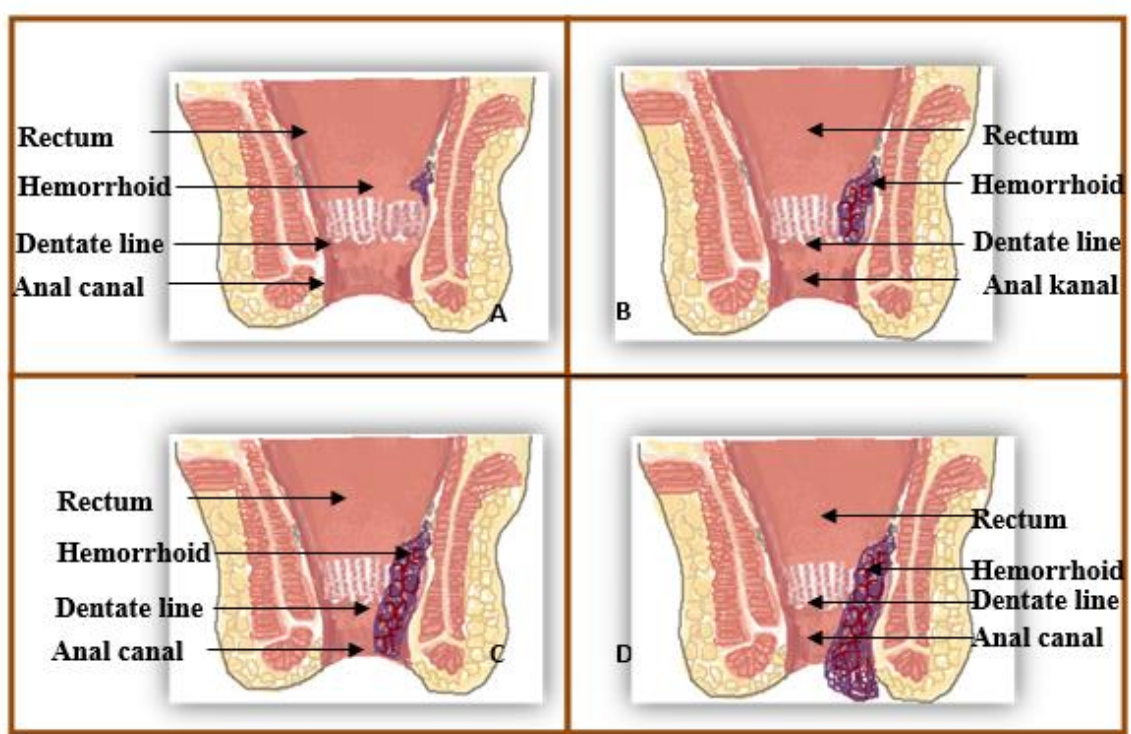

Figure 2. Internal hemorrhoids; A) 1st degree internal hemorrhoid B) 2nd degree internal hemorrhoid C) $3 r d$ degree internal hemorrhoid D) $4^{\text {th }}$ degree internal hemorrhoid 


\section{Material and Methods}

Chemicals: The chemicals were bought in Sigma Aldrich (St. Louis, MO, USA), and solvents were purchased from Merck. Croton oil was obtained from Alfa Aesar®. ELISA Kits (Rat Vascular Endothelial cell Growth Factor (VEGF) (YL Biont), Rat Tumor necrosis factor- $\alpha$ (TNF- $\alpha$ ) (YL Biont), Superoxide Dismutase (SOD)(Sigma Aldrich) are used for determining biochemical parameters.

Plant material and preparation of the extract: The all flowering plant was collected during July-August 2017 at Beysehir-KONYA region in Turkey. Only the leaves of the plants were dried in shade, then ground to powder. Powdered leaf samples (500 g) were extracted with methanol ( $1 \mathrm{~L} \mathrm{X} \mathrm{5}=5 \mathrm{~L}$ ) directly five times in room temperature. Filtered methanolic extracts were evaporated until dryness.

Animals: Local Ethical Committee, established by Kobay Laboratories with the permission of Central Ethical Committee, approved the project with the protocol number 176 (May 22, 2016). Adult male Wistar albino rats (2 months age and 180 $\pm 20 \mathrm{~g}$ weight) were used for this study. Before and during the experiments, the rats were maintained at Kobay Experimental Animals Laboratory (2017, Ankara, TURKEY) under standard experimental conditions at room temperatureand $12 \mathrm{~h}$ light: dark cycle. They were kept with a group of "7 animals/cages" and were fed with standard rodent chow and water ad libitum.

Induction of hemorrhoid: Hemorrhoid was induced by croton oil solution (containing croton oil, distilled water, pyridine and diethylether) in rats (Azeemuddin et al., 2014; Dey et al., 2016; Nishiki et al., 1988). Soft cotton swabs $(0,04 \mathrm{dm}$ diameter) soakedinto $200 \mu \mathrm{L}$ of croton oil solution were inserted in the ano-rectal section $(0,2 \mathrm{dm}$ from anal opening) of all the experimental animals and gripped for $30 \mathrm{~s}$ (Figure 3). This application was repeated once for three days. Development of edema was observed at the end of the third day of the application of croton oil solution.

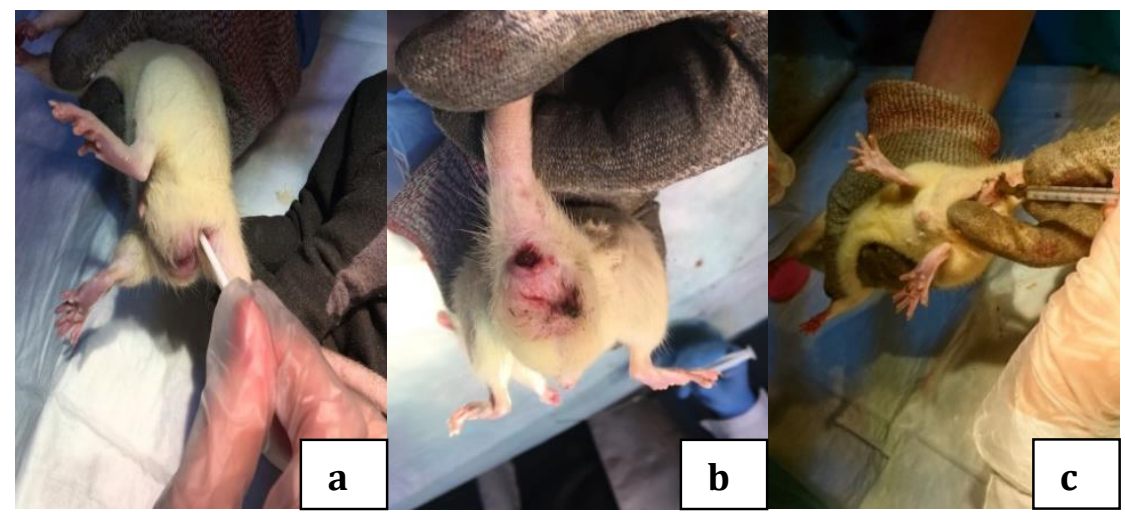

Figure 3. a) Inducing hemorrhoid b) Rectal view c) Rectal administration of the test specimens

Treatment of hemorrhoid: Following occurance of the edema, the treatment application was begun. Cold cream was preferred as a base cream. The aqueous phase of the base cream containing P. grandiflora extract dissolved in water and then that 
aqueous phase was mixed with an oily phase at a temperature of $70-80{ }^{\circ} \mathrm{C}$. The cream, which contain the plant extract was applied to the animals twice a day for 7 days.

Animal groups $(\mathbf{n}=\mathbf{7})$ :

All the treatment applications were conducted 2 times a day for 7 days

1.Control :After the occurance of edema, animals were left in the cage for 7 days without any application

2.Base cream :Externally 0,5 mL base cream,

3.Reference :Externally 0,5 mL Pilex® cream,

4.Test sample:Externally 0,5 mL P. grandiflora cream.

For evalution of the biochemical parameters, on the day 8th, intracardiac blood samples $(5 \mathrm{~mL})$ were collected from the rats under anesthesia. After the animals were sacrificed, the rats and their isolated rectoanal tissues $(0,2 \mathrm{dm}$ in length) were weighed separately (Figure 4).
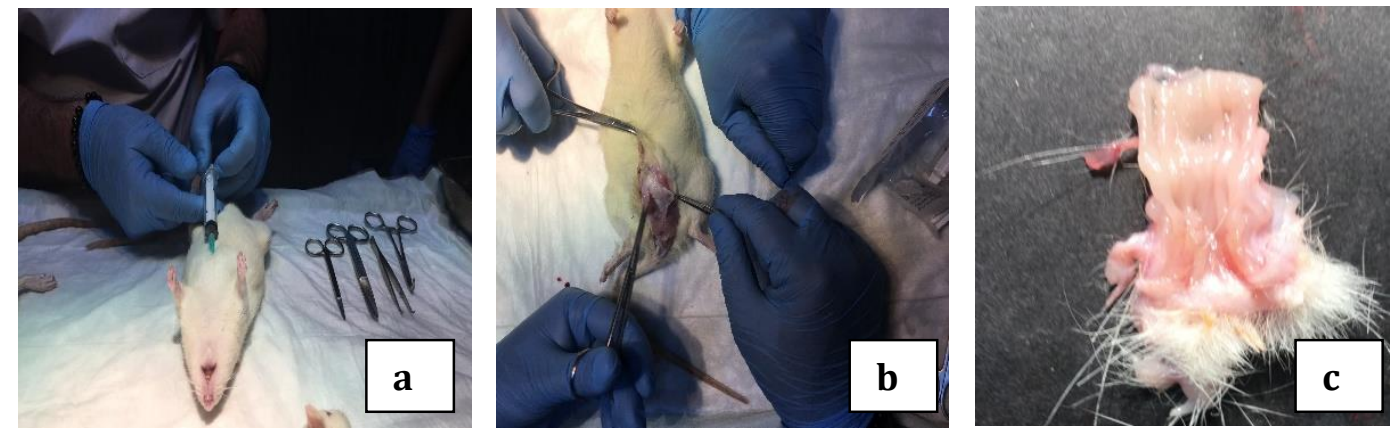

Figure 4. a) Intracardiac blood sampling b) Surgical removal of the anorectal region c) Anorectal tissue sample

Anorectal coefficient (ARC): To calculate the Anorectal coefficient (ARC), killed animals and their isolated rectoanal tissues $(0,02 \mathrm{dm}$ in length) were weighed and then the ARC was calculated by the below formula:

$$
\mathrm{ARC}=\text { Anorectal tissue weight }(\mathrm{mg}) / \text { Animal weight }(\mathrm{g})
$$

Biochemical parameters: Rat Vascular Endothelial cell Growth Factor (VEGF) ELISA Kit (YL Biont), Rat Tumor necrosis factor- $\alpha$ (TNF- $\alpha$ ) ELISA Kit (YL Biont), Superoxide dismutase (SOD) Assay Kit 500 test (Sigma Aldrich) were used for evaluating serum TNF- $\alpha$, VEGF and SOD levels. TNF- $\alpha$ and VEGF provide information about degree of inflammation. SOD is associated with the antioxidant capacity of the tissue.

\section{Chemical analysis}

Thin layer chromatography (TLC): Thin layer chromatography (TLC) was conducted to determine common phytochemical content of $P$. grandiflora medicinal plant. The combination the solvent system was Chloroform: Methanol: Water (90:10:1) and the content of the revelator was Vanillin: $\mathrm{H}_{2} \mathrm{SO}_{4}$. The spots and floresans light were viewed under the $254 \mathrm{~nm}$ and $366 \mathrm{~nm}$ by Ultraviolet light device. Phenolics and flavonoids were detected under the UV light. 
Determination of total phenoliccompounds: Total phenolic contents of the extract was determined according to Folin-Ciocalteau Method (Singleton and Rossi, 1965). Each sample was weighed ( $2 \mathrm{mg} \mathrm{mL}^{-1}$ ) and dissolved in $75 \%$ ethanol. Reference gallic acid dilutions and extract sample were mixed with $100 \mu \mathrm{L}$ Folin-Ciocalteau reagent, sodium carbonate (20\%) and distilled water. Mixtures were incubated for 30 minutes at $40^{\circ} \mathrm{C}$ and the absorbances were measured at $765 \mathrm{~nm}$. The total phenolic concentration was calculated as gallic acid equivalents using the absorbance of the samples by using calibration curve.

Determination of total flavonoids: $2 \mathrm{mg} \mathrm{mL}^{-1}$ of extract sample and moreover the reference rutin solutions were mixed with $75 \% \mathrm{EtOH}, 10 \% \mathrm{AlCl}_{3}, 1 \mathrm{M}$ sodium acetate and 2,800 $\mu \mathrm{L}$ distilled water separately. Mixtures were incubated for 30 minutes at room temperature and their absorbance was measured with a spectrophotometer at $415 \mathrm{~nm}$. Total flavonoids were calculated as rutin equivalents using the absorbance of the samples by using the calibration curve (Woisky and Salatino, 1998).

\section{Results and Discussion}

The yield of the plant extract: The yield of the methanolic plant extracts was calculated as $24,5 \%$.

Anorectal coefficient (ARC) values: ARC values of the control and the base cream groups were observed at higher levels than the reference and the plant extract groups. Among the treatment groups, the lowest ARC value was observed in the P. grandiflora extract administrated animal group showing that the treatment with the plant extract is more effective than the other groups (Table 1).

Table 1. ARC values (Mean \pm SD) of experimental groups

\begin{tabular}{|l|c|}
\hline Sample & ARC values (Mean \pm S. E. M.) \\
\hline Control & $3,53 \pm 0,11$ \\
\hline Base cream & $3,42 \pm 0,13$ \\
\hline Reference (Pilex@ cream) & $2,25 \pm 0,11^{* * *}$ \\
\hline Phlomis grandiflora $(50 \%)$ extract & $2,23 \pm 0,10^{* * *}$ \\
\hline$*: \mathrm{p}<0,05 ;^{* *}: \mathrm{p}<0,01 ;{ }^{* *}: \mathrm{p}<0,001 ;$ S.E.M.: Standarderror of themean \\
\hline
\end{tabular}

Serum TNF- $\alpha$, VEGF and SOD levels: Serum TNF- $\alpha$ and VEGF levels of the treatment groups showed a significant difference compared to the control (Table 2).

Table 2. Serum TNF- $\alpha$ and VEGF levels (Mean \pm S. E. M.) and SOD levels (Mean $\% \pm$ S. E. M) of experimental groups

\begin{tabular}{|l|l|l|c|}
\hline Sample & $\begin{array}{c}\text { TNF ALPHA } \\
\text { (Mean } \pm \text { S. E. M.) } \\
\text { (ng/L) }\end{array}$ & $\begin{array}{c}\text { VEGF } \\
\text { (Mean } \pm \text { S. E. M.) } \\
\text { (ng/L) }\end{array}$ & $\begin{array}{c}\text { SOD } \\
\text { (Mean \% } \pm \text { S. E. } \\
\text { M.) }\end{array}$ \\
\hline Control & $216,88 \pm 4,86$ & $401,09 \pm 17,77$ & $81,72 \pm 4,30$ \\
\hline Base cream & $192,79 \pm 9,66^{* *}$ & $319,45 \pm 17,71^{* * *}$ & $86,74 \pm 4,96$ \\
\hline Reference (Pilex® cream) & $186,50 \pm 3,75^{* * *}$ & $282,17 \pm 17,32^{* * *}$ & $89,51 \pm 3,45$ \\
\hline P. grandiflora $(\% 50)$ extract & $182,94 \pm 6,12^{* * *}$ & $300,67 \pm 18,71^{* * *}$ & $88,11 \pm 6,45$ \\
\hline$*: p<0,05 ;{ }^{* *}: p<0,01 ;{ }^{* *}: p<0,001 ;$ S.E.M.: Standard error of the mean \\
\hline
\end{tabular}


Among the treatment group, serum TNF- $\alpha$ level of the plant extract treated group was lower, whereas, serum VEGF level was higher than the reference. Results of serum levels were shown at Table 2. P. grandiflora extract $(88,11 \pm 6,45)$ has the most antioxidant capacity compared to the control and the base cream groups. On the other hand, SOD inhibition capacity of P. grandiflora was found close to the reference Pilex ${ }^{\circledR}$ group.

\section{Chemical Analysis}

TLC analysis: TLC results showed that leaves of $P$. grandiflora medicinal plant included chlorophyl, flavonoid and iridoid derivatives. Chlorophyl was seen as a red spot on 366 $\mathrm{nm}$. While flavonoids were seen as yellow stain after revelator spraying, iridoid derivatives and terpenic compounds were seen as purple stain. According to TLC results, the extract was rich in phenolic compounds.

Determination of total phenoliccompounds: The total phenolic content of the extract was found $12,36 \pm 1,17 \%$ as gallic acid equivalent.

Determination of total flavonoids: Total flavonoids were calculated as rutin equivalents using the absorbance of the samples. Total flavonoid content of the extract was found as $11,84 \pm 0,35 \%$.

\section{Conclusion}

In this study, the antihemmorhoidal effect of the methanolic P. grandiflora plant extract was externally examined by an in vivo model in order to confirm the by scientific research. It was determined that the plant extract applied group had a significant activity against hemorrhoid when compared with control group, base cream and reference Pilex ${ }^{\circledR}$ cream applied groups According to the calculated ARC scores methanolic extract of $P$. grandiflora with, showed higher biological activity than the base cream and the reference preparation. P. grandiflora methanolic leaf extract caused a decrease in serum levels of the pro-inflammatory cytokine TNF- $\alpha$ compared the control group. VEGF, which is a five apart gene product, is closely related to capillary permeability. Decrease in the level of VEGF in serum might indicate that the extract might be decreasing the capillary permeability rather than any direct effect on angiogenesis and anti-inflammatory effect (Bates, 2010). Our SOD results confirmed that antioxidant capacity might support various biological activities including antihemorrhoidal effect. When all the data were evaluated together, the plant has been shown to have a promising effect on hemorrhoids. In addition, the determination of the major group of compounds in the plant extract and quantification of the group of substances thought to be responsible for the activity were carried out. In this and previous studies, it was determined that P. grandiflora had high total phenol content (Koca-Çalışkan et al., 2017a). The compounds responsible for the activity might be phenolics such as flavonoids or iridoid glycosides, which are major in the plant (SSenol et al., 2018). Moreover, according to literature review, phenolic/flavonoid composition of the plant might have activity through inducing capillary permeability (Koca-Çalışkan et al., 2017b).

In conlusion, the methanolic extract of P. grandiflora can be considered as a promising antihemorrhoidal natural source. This study can be a guide to the studies on the 
elucidation of the antihemoroidal activity of $P$. grandiflora and the formulation of a natural novel topical formulation.

Acknowledgments: We would like to thank Gazi University Scientific Research Projects Unit for its project (02/2016-03 code number) fund support. We would like to thank Vet. Salih Salar from Kobay Experimental Animals Laboratory.

Disclosure of Conflicts of Interest: The authors declare no conflict of interest/no competing financial interests exist.

\section{References}

Abascal, K., and Yarnell, E., 2005. Botanical treatments for hemorrhoids. Alternative \& Complementary Therapies, 11(6), 285-289.

Aka-Dönmez, C., Boyacıoğlu, Ö., Korkusuz, P., and Koca-Çalışkan, U., 2019. The Fifth International Mediterranean Symposium on Medicinal and Aromatic Plants. In: From a Traditional Remedy to Modern therapy; in vivoAntihemorrhoidal Studyof Malva sylvestris L.,MESMAP-5,Nevșehir,260-265.

Amor, I.L.B., Boubaker, J., Sgaier, M.B., Skandrani, I., Bhouri, W., Neffati, A., Kilani, S., Bouhlel, I., Ghedira, K. and Chekir-Ghedira, L., 2009. Phytochemistry and biological activities of Phlomis species. Journal of Ethnopharmacology, 125(2), 183-202.

Azeemuddin, M., Viswanatha, G.L., Rafiq, M., Thippeswamy, A.H., Baig, M.R., Kavya, K. J., and Shyam, R., 2014. An improved experimental model of hemorrhoids in rats: evaluation of antihemorrhoidal activity of an herbal formulation. ISRN Pharmacology, 2014, 1-7.

Bates, D.0., 2010. Vascular endothelial growth factors and vascular permeability. Cardiovascular Research, 87(2), 262-271.

Çelik, S., Göktürk, R. S., Flamini, G., Cioni, P. L., and Morelli, I., 2005. Essential oils of Phlomis leucophracta, Phlomis chimerae and Phlomis grandiflora var. grandiflora from Turkey. Biochemical Systematics and Ecology, 33(6), 617-623.

Demirci, F., Guven, K., Demirci, B., Dadandi, M.Y., and Baser, K.H.C., 2008. Antibacterial activity of two Phlomis essential oils against food pathogens. Food Control, 19(12), 1159-1164.

Dey, Y.N., Wanjari, M.M., Kumar, D., Lomash, V., andJadhav, A.D., 2016. Curativeeffect of Amorphophallus paeoniifolius tuber on experimental hemorrhoids in rats. Journal of Ethnopharmacology, 192, 183-191.

Dönmez, C., 2019. Pharmacognosic researches on Solanum melongena L. used against hemorrhoid as folk remedy [Halk arasında hemoroide karşı kullanılan Solanum melongena L. bitkisi üzerinde farmakognozik araștırmalar], (PhD Thesis), Gazi Univ., Dept. of Pharmacognosy, Ankara, 65-85.

Gürbüz, İ., Üstün, O., Yesilada, E., Sezik, E., and Kutsal, O., 2003. Anti-ulcerogenic activity of some plants used as folk remedy in Turkey. Journal of Ethnopharmacology, 88(1), 93-97.

Koca-Çalışkan, U., Aka, C., Anlaş, F.C., Üstün-Alkan, F., and Üstüner, O., 2017a. Mediterranean Symposium on Medicinal and Aromatic Plants. In: The Antioxidant and Proliferative Activities of Different Extracts from Some Medicinal Plants on Mouse Fibroblast Cells. MESMAP, 3, Kyrenia, 235.

Koca-Çalışkan, U., Aka, C., and Oz, M.G., 2017b. Plants used in Anatolian traditional medicine for the treatment of hemorrhoid. Records of Natural Products, 11(3), 235-250.

Nishiki, K., Nishinaga, K., Kudoh, D., and Iwai, K., 1988. Croton oil-induced hemorrhoid model in rat: comparison of anti-inflammatory activity of diflucortolone valerate with other glucocorticoids. Nihonyakurigakuzasshi. Folia Pharmacologica Japonica, 92(4), 215-225.

Şenol, F.S., Günbatan, T., Öztürk, N., Gürbüz, İ., and Orhan, İ.E., 2018. Phenolic acid profile and in vitro neurobiological effect of Phlomis grandiflora HS Thompson var. grandiflora. Journal of the Chemical Society of Pakistan, 40(1), 129-138.

Singleton, V.L., and Rossi, J.A., 1965. Colorimetry of total phenolics with phosphomolybdicphosphotungstic acid reagents. American Journal of Enology and Viticulture, 16, 144-158.

Takeda, Y., Kinugawa, M., Masuda, T., Honda, G., Otsuka, H., Sezik, E., and Yesilada, E., 1999. Phlomisethanoside, a phenylethanoid glycoside from Phlomis grandiflora var. grandiflora. Phytochemistry, 51(2), 323-325.

Varut, L., 2012. Hemorrhoids: from basic pathophysiology to clinical management. World Journal of Gastroenterology, 18(17), 2009-2017.

Woisky, R.G., and Salatino, A., 1998. Analysis of propolis: some parameters and procedures for chemical quality control. Journal of Apicultural Research, 37, 99-105. 